\title{
Leukemoid reaction: Case report
}

Trevor A. Ellison, MD, PhD, and Kaushik Mandal, MBBS, MD, Baltimore, Md

\author{
From the Division of Cardiac Surgery, Department of Surgery, The Johns Hopkins Hospital, Baltimore, Md. \\ Disclosures: Authors have nothing to disclose with regard to commercial support. \\ Received for publication April 4, 2017; revisions received Aug 2, 2017; accepted for publication Aug 29, 2017; \\ available ahead of print Feb 1, 2018. \\ Address for reprints: Kaushik Mandal, MBBS, MD, Division of Cardiac Surgery, Department of Surgery, The \\ Johns Hopkins Hospital, 600 N Wolfe St, Sheikh Zayed Tower Suite 7107, Baltimore, MD 21287 (E-mail: \\ kmandal2@jhmi.edu). \\ J Thorac Cardiovasc Surg 2018;155:e117-8 \\ $0022-5223 / \$ 36.00$ \\ Copyright (C) 2017 by The American Association for Thoracic Surgery \\ https://doi.org/10.1016/j.jtcvs.2017.08.125
}

Video clip is available online.

A leukemoid reaction is defined as a leukocytosis exceeding 50,000 cells $/ \mu \mathrm{L}$ accompanied by an increase in neutrophil precursors. ${ }^{1}$ Etiologies include hematologic malignancies, paraneoplastic syndromes of nonhematologic malignancies, and noncancerous entities (Table 1). ${ }^{1,2}$ It is difficult to determine the exact incidence of leukemoid reaction in hospitalized patients, as the literature is scarce, but a recent paper identified 173 patients without hematologic malignancies and with leukemoid reaction. The incidence of leukemoid reaction (defined as white blood count [WBC] $\geq 30,000$ cells $/ \mu \mathrm{L}$ in the aforementioned paper) was $0.59 \%$ of consecutive hospital admissions. ${ }^{3}$ This same paper found that although infection was the most common cause in $48 \%$ of the cases, ischemia/stress and inflammation was the causative agent in another $28 \%$ and $7 \%$, respectively. ${ }^{3}$ A correlation between a patient's circulation through the cardiopulmonary bypass machine circuit and the patient's inflammatory response has been proposed as mediated by inflammatory mediators as well as reperfusion injury. ${ }^{4}$ We present a case of a 72-year-old woman, after having obtained her signature consent, who underwent tissue valve replacement of her aortic valve and had a subsequent leukemoid reaction with no signs of infection or malignancy (Video 1).

\section{CLINICAL SUMMARY}

A 72-year-old woman with symptomatic aortic stenosis (mean pressure gradient of $61 \mathrm{~mm} \mathrm{Hg}$ and a measured valve area of $0.7 \mathrm{~cm}^{2}$ ) underwent an uncomplicated surgical aortic valve replacement with a $23-\mathrm{mm}$ tissue valve via median sternotomy. Cardiac protection included cooling,

2. Malignancies

c. Melanoma

d. Sarcoma

3. Drugs

a. Corticosteroids

b. Minocycline

4. Intoxication

a. Ethylene glycol

6. Miscellaneous

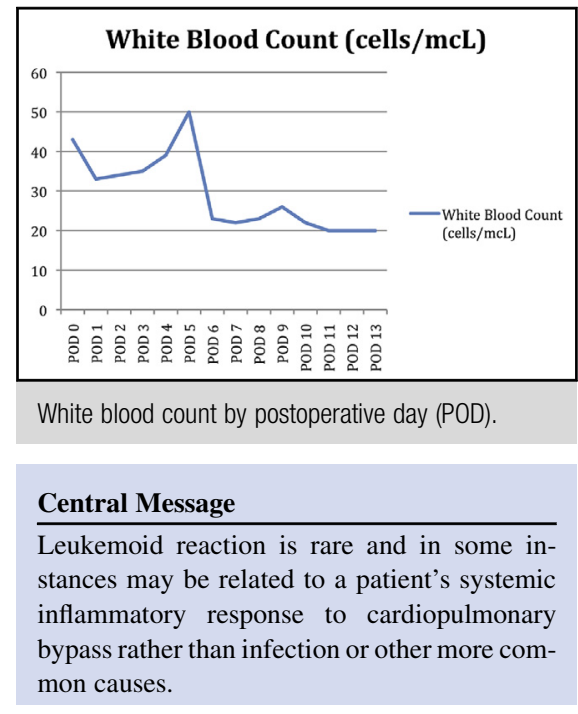

See Editorial Commentary page e119.

del Nido cardioplegia instilled in both ante- and retrograde fashion, and topical ice slurry. The valve was sewn in with 14 inverting 2-0 nonabsorbable, braided-polyester, plegeted sutures via a titanium suture-fastening device. She came off cardiopulmonary bypass on $0.05 \mu \mathrm{g} / \mathrm{kg} / \mathrm{min}$ of epinephrine with no defibrillation. A postoperative transesophageal

TABLE 1. Major causes of leukemoid reaction (reproduced with permission, personal communication) ${ }^{2}$

Major causes of leukemoid reaction

1. Infections (some major examples are listed)
a. Clostridium difficile colitis
b. Disseminated tuberculosis
c. Severe shigellosis

a. Carcinoma (lung, oropharyngeal, gastrointestinal, genitourinary)

b. Hodgkin lymphoma

c. Recombinant hematopoietic growth factors

5. Severe hemorrhage or acute hemolysis

a. Retroperitoneal hemorrhage

a. Mesenteric inflammatory pseudotumor

b. Alcoholic steatohepatitis 


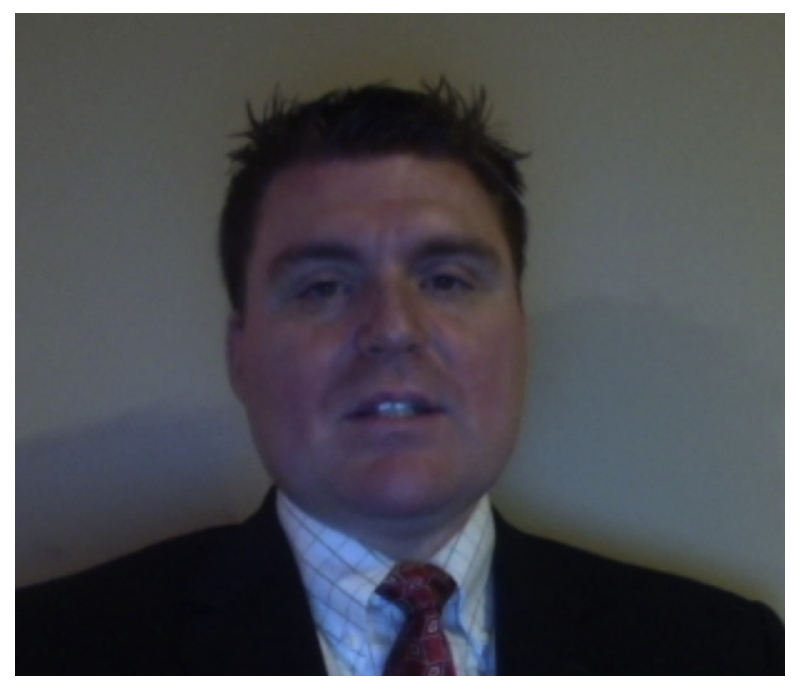

VIDEO 1. First author, Trevor Ellison, describes the importance and relevance of this case report. Video available at: http://www.jtcvsonline.org/ article/S0022-5223(17)31900-1/fulltext.

echocardiogram showed a well-seated aortic valve with no paravalvular leak and a mean transvalvular gradient of $12 \mathrm{~mm} \mathrm{Hg}$.

The patient's postoperative course was notable for atrial fibrillation, a right pleural effusion that was drained, and a persistent leukocytosis through discharge on postoperative day (POD) 13. The patient was transferred to the floor on POD 1, and while she remained afebrile for her entire hospital course, her postoperative WBC was 43,000 cells $/ \mu \mathrm{L}$ from a preoperative WBC of 10,900 cells $/ \mu \mathrm{L}$. By POD 5, her WBC had increased up to 50,000 cells $/ \mu \mathrm{L}$ ( $83 \%$ neutrophils) (Figure 1 ).

As the result of her elevated $\mathrm{WBC}$, an extensive infectious workup was performed, and she was treated with an extra 7 days of antibiotics (cefazolin on POD 0-1, ceftriaxone on POD 3-4, and piperacillin-tazobactam on POD 5-9). She had her central line removed POD 3 and then re-sited on POD 5, her urinary catheter was removed, microbiology specimens were sent (peripheral blood cultures, a urine culture, and pleural effusion fluid), a heparin-induced thrombocytopenia panel was ordered, a computed tomography scan of the chest, abdomen, and pelvis was performed, amylase and lipase were sent, stool was not cultured as she did not have frequent nor loose stool, and she was examined regularly for any signs of wound infection. Her entire workup remained negative except some mild phlebitis on her right forearm through to her discharge.

\section{DISCUSSION}

Leukemoid reaction in a postoperative cardiac patient is concerning for infectious etiology or an unmasked hematologic malignancy. ${ }^{5}$ However, leukemoid reactions

\section{White Blood Count (cells/mcL)}

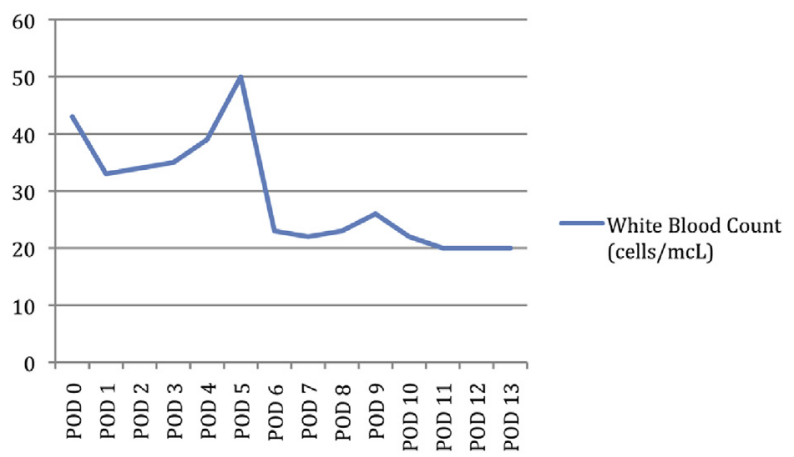

FIGURE 1. White blood count by POD. POD, Postoperative day.

can be ascribed to large number of noninfectious and nonhematologic malignancy etiologies (Table 1). ${ }^{1,2}$ Pertinent to cardiac surgery is that a leukemoid reaction can be caused by the systemic inflammation from the cardiopulmonary bypass circuit. While the leukocytosis may persist, the leukemoid reaction where the WBC is $>50,000$ cells $/ \mu \mathrm{L}$ lasts for 1 day or less in the majority of patients. $^{3}$

There is obvious reason for concern for infection in a postoperative patient with a large leukocytosis, although there may be no correlation between the degree of leukocytosis and survival. ${ }^{3}$ However, there is a correlation between infectious etiology of a leukemoid reaction and mortality, as one paper showed that of the $38 \%$ in-hospital mortality rate among their patients with leukemoid reaction, the most highly correlated factors with death were age, sepsis, and any infectious diagnosis. ${ }^{3}$

Leukemoid reaction is a postcardiac surgery diagnosis that must be kept in mind in the face of an extremely elevated WBC to mitigate the risks and financial costs of unnecessary, prolonged hospital stays and antibiotic courses in those with leukemoid reaction. Although leukemoid reaction is not known to be preventable in this instance, as it is an idiopathic response to the cardiopulmonary bypass circuit, its diagnosis can be facilitated by workup for and exclusion of those entities found in Table 1.

\section{References}

1. Padmakumar G, Ravikrishnan J, Jayakumar P, Prasad K. Leukemoid like reaction in post CABG patient. Indian J Anaesth. 2014;58:315-8.

2. Sakka V, Tsiodras S, Giamarellos-Bourboulis J, Giamarellou H. An update on the etiology and diagnostic evaluation of a leukemoid reaction. Eur J Intern Med. 2006; 17:394-8.

3. Potasman I, Grupper M. Leukemoid reaction: spectrum and prognosis of 173 adult patients. Clin Infect Dis. 2013;57:e177-81.

4. Levy J, Tanaka K. Inflammatory response to cardiopulmonary bypass. Ann Thorac Surg. 2003;75:S715-20.

5. Drury NE, Ali A, Mussa S, Webb ST, Rege KP, Wallwork J. Acute leukaemoid reaction following cardiac surgery. J Cardiothorac Surg. 2007;2:3. 